\title{
The efficacy and safety of peripheral intravenous parenteral nutrition vs $10 \%$ glucose in preterm infants born 30 to 33 weeks' gestation: a randomised controlled trial
}

\author{
Hiroki Suganuma ${ }^{1,2+}$, Dennis Bonney ${ }^{3+}$, Chad C. Andersen ${ }^{3}$, Andrew J. McPhee ${ }^{1,3}$, Thomas R. Sullivan ${ }^{1,4}$,
} Robert A. Gibson ${ }^{1,5}$ and Carmel T. Collins ${ }^{1,2^{*}}$ (D)

\begin{abstract}
Background: Preterm infants born 30 to 33 weeks' gestation often require early support with intravenous fluids because of respiratory distress, hypoglycemia or feed intolerance. When full feeds are anticipated to be reached within the first week, risks associated with intravenous delivery mode and type must be carefully considered. Recommendations are for parenteral nutrition to be infused via central venous lines (because of the high osmolarity), however, given the risks associated with central lines, clinicians may opt for 10\% glucose via peripheral venous catheter when the need is short-term. We therefore compare a low osmolarity peripheral intravenous parenteral nutrition (P-PN) solution with peripheral intravenous 10\% glucose on growth rate in preterm infants born 30 to 33 weeks' gestation.

Methods: In this parallel group, single centre, superiority, non-blinded, randomised controlled trial, 92 (P-PN 42, control 50) infants born $30^{+0}$ to $33^{+6}$ weeks' gestation, were randomised within $24 \mathrm{~h}$ of age, to receive either P-PN (8\% glucose, $30 \mathrm{~g} / \mathrm{L}$ amino acids, $500 \mathrm{IU} / \mathrm{L}$ heparin and SMOFlipid ${ }^{\oplus}$ ) or a control of peripheral intravenous 10\% glucose. Both groups received enteral feeds according to hospital protocol. The primary outcome was rate of weight gain from birth to 21 days of age.

* Correspondence: carmel.collins@sahmri.com

${ }^{\dagger}$ Hiroki Suganuma and Dennis Bonney contributed equally to this work.

'SAHMRI Women and Kids, South Australian Health and Medical Research

Institute Adelaide, South Australia, Australia

${ }^{2}$ Discipline of Paediatrics, Adelaide Medical School, The University of

Adelaide, Adelaide, SA, Australia

Full list of author information is available at the end of the article

C The Author(s). 2020 Open Access This article is licensed under a Creative Commons Attribution 4.0 International License, which permits use, sharing, adaptation, distribution and reproduction in any medium or format, as long as you give appropriate credit to the original author(s) and the source, provide a link to the Creative Commons licence, and indicate if changes were made. The images or other third party material in this article are included in the article's Creative Commons licence, unless indicated otherwise in a credit line to the material. If material is not included in the article's Creative Commons licence and your intended use is not permitted by statutory regulation or exceeds the permitted use, you will need to obtain permission directly from the copyright holder. To view a copy of this licence, visit http://creativecommons.org/licenses/by/4.0/ The Creative Commons Public Domain Dedication waiver (http://creativecommons.org/publicdomain/zero/1.0/) applies to the data made available in this article, unless otherwise stated in a credit line to the data. 
(Continued from previous page)

Results: The rate of weight gain was significantly increased in P-PN infants compared with control (P-PN, $n=42$, 18.7, SD $6.6 \mathrm{~g} / \mathrm{d}$ vs control, $n=50,14.8, \mathrm{SD} 6.0 \mathrm{~g} / \mathrm{d}$; adjusted mean difference $3.9 \mathrm{~g} / \mathrm{d}, 95 \% \mathrm{Cl} 1.3$ to $6.6 ; P=0.004$ ), with the effect maintained to discharge home. Days to regain birthweight were significantly reduced and length gain significantly increased in P-PN infants. One infant in the P-PN group had a stage 3 extravasation which rapidly resolved. Blood urea nitrogen and triglyceride levels were significantly higher in the P-PN group in the first week of life, but there were no instances of abnormally high levels. There were no significant differences in any other clinical or biochemical outcomes.

Conclusion: P-PN improves the rate of weight gain to discharge home in preterm infants born 30 to 33 weeks gestation compared with peripheral intravenous 10\% glucose.

Trial registration: Australian New Zealand Clinical Trials Registry ACTRN12616000925448. Registered 12 July 2016.

Keywords: Preterm infant, Parenteral nutrition, Intravenous lipids

\section{Background}

Infants born 30 to 33 weeks' gestation constitute approximately $2-3 \%$ of the infant population and a large proportion of neonatal admissions. This population of preterm infants often requires transient respiratory support, are at risk of hypoglycemia and feed intolerance such that intravenous fluids are often provided during the early stages of their care. This early neonatal period corresponds to a critical window during which under-nutrition may have long lasting effects on growth and development. Lower intelligence quotient and more attention and behavioral problems at school age are evident not only in very preterm infants [1] but also in moderately preterm infants [2-4] when compared with infants born at term. We, and others, have shown that in-hospital growth is related to later developmental outcome and that improvements in growth rate are associated with better mental development $[5,6]$.

Although recommendations for early parenteral amino acids and lipid support for very preterm infants $(<32$ weeks' gestation) are clear $[7,8]$, the nutritional requirements of the moderately preterm infant (32 to 33 weeks' gestation) are less well established [9]. While practices vary, in many centres moderately preterm infants receive $10 \%$ glucose using a peripheral intravenous cannula in the first week of life as enteral feeds are established [10, 11]. Parenteral nutrition solutions are typically given via central venous catheters due to their high osmolarity and risks with extravasation if delivered peripherally [12-15]. However, central venous lines are not without risk and consequently infants requiring them are cared for in intensive care settings $[12,13]$. Most moderately preterm newborns $[10,11]$, and in our experience even many less mature infants (30 to 31 weeks' gestation), do not get central venous catheters as they are considered physiologically stable enough to be able to tolerate full enteral nutrition by 5-7 days of age and thus can be cared for in Special Care Units [10, 11]. Although recent recommendations state that peripheral venous parenteral nutrition can be given for short periods, the level of evidence for this is low and the risks associated with extravasation high [13, 14]. In addition recommendations state that peripheral venous delivery should only be used when the osmolarity of the infusate is < 850-900 $\mathrm{mOsm} / \mathrm{L}[13,15]$.

Consequently, these infants receive less protein and lipid nutrition in the first week of life in comparison to both in-utero accretion and their more immature exutero counterparts. Clinicians therefore are balancing the risks associated with the use of central venous lines to deliver parenteral nutrition with the risks associated with short term poorer nutrition as full enteral feeds are established. We therefore aimed to determine the efficacy and safety of providing peripherally administered, low osmolarity, intravenous parenteral nutrition to preterm infants born 30 to 33 weeks' gestation.

\section{Methods \\ Study design}

The study was a single centre (Women's and Children's Hospital, North Adelaide, South Australia), parallel group, superiority, randomised controlled trial conducted between September 2016 and June 2018. The trial protocol was approved by the Human Research Ethics Committee (HREC/15/WCHN/134) of the Women's and Children's Hospital and the study was registered with the Australian New Zealand Clinical Trials Registry (ACTRN12616000925448). The study adheres to CONSORT guidelines for reporting of randomised controlled trials [16].

\section{Participants}

Infants born $30^{+0}$ to $33^{+6}$ weeks' gestation at the Women's and Children's Hospital who required intravenous fluids and were less than $24 \mathrm{~h}$ of age and whose parents were able to provide informed written consent, were eligible to participate. Multiple births were eligible and were randomised individually. Infants receiving fluids administered centrally or presenting with major 
congenital or chromosomal abnormalities were ineligible. Infants were required to be enrolled and randomised before $24 \mathrm{~h}$ of age.

\section{Randomisation and blinding}

Infants were randomised to one of two groups: the peripheral parenteral nutrition (P-PN) group or control (peripheral $10 \%$ glucose) with a 1:1 allocation according to a computer-generated randomisation schedule developed by an independent statistician. Originally the schedule was to be stratified by sex and gestational age $30^{+0}$ to $31^{+6}$ and $32^{+0}$ to $33^{+6}$ weeks' using permuted blocks of random sizes. Unfortunately, during development, the sequence of randomisations within each stratum was unintentionally re-sorted according to a randomly generated uninformative study identifier; this was not discovered until the study was complete. This essentially nullified the effects of blocking and meant the final randomisation procedure most closely approximated simple randomisation.

Parents of eligible infants were approached by a clinician (medical practitioner or neonatal nurse practitioner) and followed-up for consent by a research nurse who was not involved in clinical care. Upon consent, infants were randomised by a research nurse or clinician using REDCap (Research Electronic Data Capture) - a secure web-based software platform hosted at the South Australian Health and Medical Research Institution [17, 18]. Data analysts were blinded to group allocation. It was not possible to blind families, clinicians and the researchers who conducted data collection.

\section{Interventions}

The intervention P-PN solution was prepared by Baxter Healthcare and contained amino acids (as Primene $\left.{ }^{\circ}\right) 30$ $\mathrm{g} / \mathrm{L}$, glucose $80 \mathrm{~g} / \mathrm{L}(8 \%)$ and heparin $500 \mathrm{IU} / \mathrm{L}$. The PPN solution was provided in $400 \mathrm{~mL}$ bags and had an estimated osmolality of $678 \mathrm{mOsm} / \mathrm{L}$. The intervention was given to a maximum of $100 \mathrm{~mL} / \mathrm{kg} / \mathrm{d}$, so the infant received a maximum intravenous protein intake of $3 \mathrm{~g} /$ $\mathrm{kg} / \mathrm{d}$. If additional parenteral fluid was required to maintain the targeted total fluid volume or for physiological homeostasis, $10 \%$ glucose was given as a separate line via the same peripheral intravenous site. The lipid solution was a $17 \%$ lipid emulsion with added vitamins for administration (SMOFlipid ${ }^{\circ}$ 20\% $15 \mathrm{~mL}$, Vitalipid N Infant $^{\circ} 4 \mathrm{~mL}$ and Soluvit $\mathrm{N}^{\odot} 1 \mathrm{~mL}$ per $20 \mathrm{~mL}$, Fresenius Kabi) with the estimated osmolality of $340 \mathrm{mOsm} / \mathrm{L}$. The lipid emulsion (with vitamins) was administered using a separate line via the same peripheral intravenous site at $2 \mathrm{~g} / \mathrm{kg} / \mathrm{d}$ and was included in the total amount of intravenous daily fluids. For the period prior to randomisation and commencement of the intervention solutions, infants received intravenous $10 \%$ glucose via peripheral venous catheter.

The control group received peripheral intravenous $10 \%$ glucose (osmolarity $556 \mathrm{mOsm} / \mathrm{L}$ ) administered as per the Women's and Children's Hospital neonatal fluid management guidelines. Electrolytes were added, if clinically indicated, using a commercially available premixed solution (Glucose $100 \mathrm{~g} / \mathrm{L}$, Potassium chloride $1.5 \mathrm{~g} / \mathrm{L}$, Sodium chloride $2.25 \mathrm{~g} / \mathrm{L}$; osmolarity $672 \mathrm{mOsm} / \mathrm{L}$ ).

The fluid management approach was the same for both groups and followed the Hospital guidelines with total fluid volume commenced at $60 \mathrm{~mL} / \mathrm{kg} / \mathrm{d}$, increasing by $10-15 \mathrm{~mL} / \mathrm{kg} / \mathrm{d}$ to $150-170 \mathrm{ml} / \mathrm{kg} / \mathrm{d}$. Enteral feeds (typically expressed breast milk, EBM, or less commonly preterm formula when EBM not available) are commenced when clinically stable. EBM is typically fortified when the enteral intake is $>80 \mathrm{~mL} / \mathrm{kg} / \mathrm{d}$. The IV infusions ceased in both the intervention and control groups when an enteral intake of $120 \mathrm{~mL} / \mathrm{kg} / \mathrm{d}$ was reached and maintained for 3 days. Lipid emulsion was administered at $2 \mathrm{~g} / \mathrm{kg} / \mathrm{d}$ and ceased at an enteral intake of $100 \mathrm{~mL} /$ $\mathrm{kg} / \mathrm{d}$. Fluid balance records were audited daily for compliance with the trial protocol. Peripheral venous cannulae were routinely changed every $72 \mathrm{~h}$.

\section{Outcome assessments}

The primary outcome was weight gain $(\mathrm{g} / \mathrm{d})$ from birth to 21 days \pm 2 days. Body weight was measured by clinical staff at approximately the same time daily using electronically balanced scales. Secondary efficacy outcomes included: weight $(\mathrm{g} / \mathrm{d})$, length and head circumference gain $(\mathrm{mm} / \mathrm{d})$ from birth to discharge home; weight, length and head circumference at 21 days of age \pm 2 days and on discharge home. Length was measured weekly and on day of discharge home by clinical staff using a recumbent length board measured to the nearest $0.1 \mathrm{~cm}$. Head circumference was measured around the largest occipitofrontal circumference, using a non-stretching tape, weekly and on day of discharge home by clinical staff. Secondary safety outcomes included extravasation stage 3 or 4 [19], the number of infants requiring central venous catheter insertion, duration of peripheral venous cannula, feeding tolerance (the number of days on which one or more feeds were stopped) and the number of days taken to reach enteral intake $\geq 120 \mathrm{~mL} / \mathrm{kg} / \mathrm{d}$ and maintained for 3 days. Clinical outcomes included confirmed sepsis, days of any respiratory support and length of hospital stay (collected according to the Australian and New Zealand Neonatal Network data definitions) [20].

Protein, lipid and energy intake over the first 21 days were assessed. Parenteral and enteral intake data were collected prospectively from fluid balance charts. The macronutrient composition of the intravenous solutions and formula were based on manufacturer information, 
and human milk on published values [21]. Energy intake was calculated using the Atwater factors of 4, 4 and 9 kcal per gram of protein, carbohydrate and fat, respectively. Blood samples were taken to assess protein and lipid safety on study day 1, 2, 4, 7, 14 and 21 . Blood urea nitrogen (BUN), albumin, triglycerides, $\mathrm{pH}$, base excess and blood glucose levels were measured at hospital laboratories. All data were entered into REDCap [17, 18].

\section{Sample size and statistical analysis}

Assuming a standard deviation in weight gain of $5 \mathrm{~g}$ per day in this population [22], 45 infants per group (total of 90 infants) were required to detect a difference in weight gain of $3 \mathrm{~g}$ per day between groups with $80 \%$ power $(P<$ $0.05)$. Consultation with the neonatal medical team agreed that this was a clinically important difference on which clinical practice would change.

All analyses were carried out on an intention to treat basis according to a pre-specified statistical analysis plan. Weight gain from birth to 21 days was compared between groups using linear regression, with adjustment made for sex and gestational age at birth $\left(30^{+0}\right.$ to $31^{+6}$ and $32^{+0}$ to $33^{+6}$ weeks) and generalised estimating equations used to account for clustering due to multiple births. Secondary efficacy and safety outcomes were compared between groups using linear, logistic, and negative binomial regression models as appropriate, again using generalised estimating equations to account for clustering due to multiple births. Secondary biochemical measures obtained from the blood samples and weight $\mathrm{z}$-scores were compared between groups over time using linear mixed models, with fixed effects terms for group, time and the interaction between group and time included in each model. For the primary outcome only, a per-protocol analysis including only those infants whose clinical care adhered to the study protocol (i.e. received P-PN and control solutions via peripheral line) was also undertaken. We calculated z-scores for weight using Australian standards [23]. All analyses were performed using R 3.5.1 (R Core Team, 2019) [24].

\section{Results}

\section{Trial population}

Ninety-two infants were enrolled in the study with 42 infants randomised to the P-PN group and 50 infants to the control (Fig. 1). In total, four infants (P-PN 3, control 1) required central venous line insertion due to their clinical condition and commenced 'standard preterm PN' [25] (Baxter Healthcare Pty Ltd) and SMOFlipid'. All 92 infants were included in intention-to-treat analyses with 88 infants included in the per-protocol analysis. Baseline demographic and clinical characteristics were similar between the groups, although there were more singleton infants randomised to the control group than the P-PN group (Table 1 and Supplementary Table 1, Additional File).

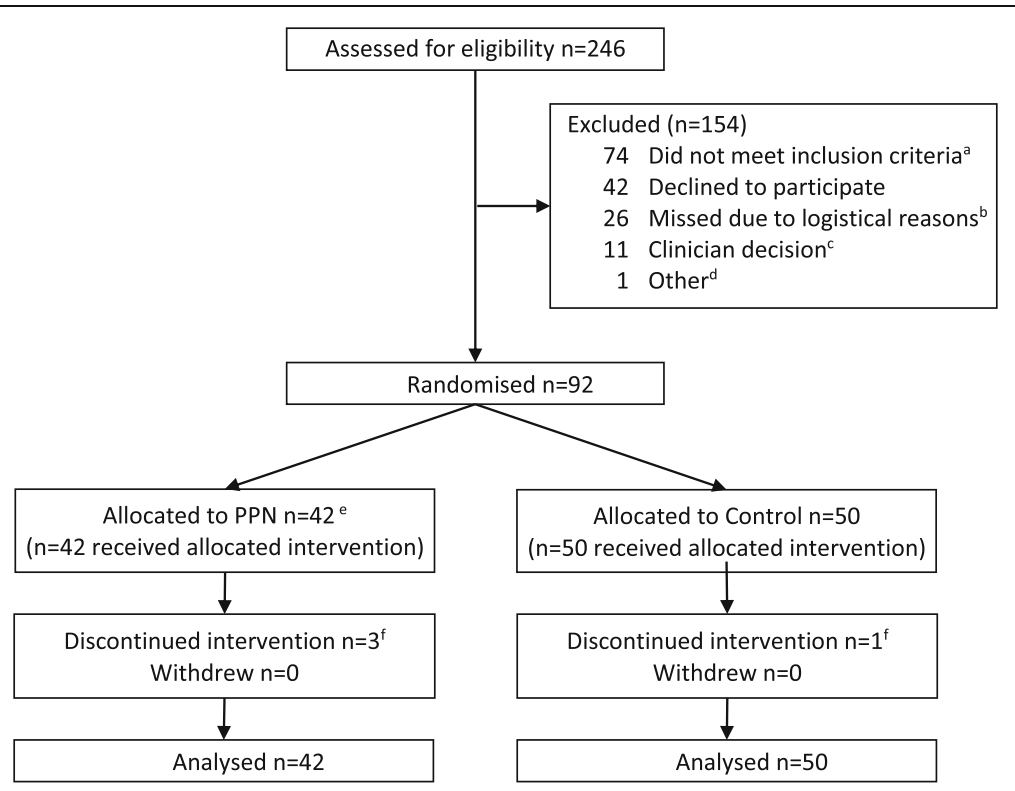

Fig. 1 Participant flow through the study. ${ }^{a}$ Did not meet gestational age criteria $n=2$, Out born $n=13$, Central line placed, or anticipated to be placed, within $24 \mathrm{~h} n=35$, Congenital or chromosomal abnormality $n=7$, $>24 \mathrm{~h}$ of age $n=1$, Language difficulty $n=7$, Parent $<18$ years of age $n=2$, Did not require IV $n=1$, IV for $<24 h n=1$, Imminent transfer to stepdown hospital $n=3$, Died $n=1$, Insufficient study product available $n=1$. ${ }^{\text {b }}$ Staff not available $n=26$. ${ }^{c}$ Anticipated to reach full enteral feeding within 3 days $n=10$, given glucagon $n=1$. ${ }^{d}$ No decision made by the parents within $24 \mathrm{hn}=1$. ${ }^{e}$ One out born infant randomised in error and included in all analyses. ${ }^{f}$ Discontinued the study fluids due to clinical condition and need for central line insertion - commenced standard PN and SMOFlipid ${ }^{\oplus}$ 
Table 1 Baseline demographic and clinical characteristics

\begin{tabular}{|c|c|c|}
\hline Variable & P-PN $(n=42)$ & Control $(n=50)$ \\
\hline \multicolumn{3}{|l|}{ Infant characteristics } \\
\hline Female sex & $17(40)$ & $17(34)$ \\
\hline Gestational age, median (IQR), wks & $32(31-32)$ & $32(31-33)$ \\
\hline $30^{+0}-31^{+6}$ weeks' gestation & $15(36)$ & $19(38)$ \\
\hline $32^{+0}-33^{+6}$ weeks' gestation & $27(64)$ & $31(62)$ \\
\hline Singleton & $18(43)$ & $32(64)$ \\
\hline Twins & $18(43)$ & $15(30)$ \\
\hline Triplets & $6(14)$ & $3(6)$ \\
\hline Apgar at $5 \mathrm{~min}$, median (IQR) $(n=41 / 50)$ & $9.0(8.0-9.0)$ & $8.5(8.0-9.0)$ \\
\hline Birth weight, mean (SD), g & $1717(289)$ & 1749 (329) \\
\hline Birth weight z-score, mean (SD) & $-0.2(0.7)$ & $-0.1(0.7)$ \\
\hline Birth length, mean (SD), cm & $42(2)$ & $42(2)$ \\
\hline Birth head circumference, mean (SD), cm & $30(2)$ & $30(2)$ \\
\hline \multicolumn{3}{|l|}{ Maternal characteristics } \\
\hline Maternal age, mean (SD), yr & $32(5)$ & $31(5)$ \\
\hline Vaginal birth & $14(33)$ & $15(30)$ \\
\hline Caesarean section & $28(67)$ & $35(70)$ \\
\hline Antenatal steroids - any & $24(57)$ & $35(70)$ \\
\hline
\end{tabular}

Data are presented as $\mathrm{n}(\%)$ unless otherwise indicated

\section{Nutritional management}

All infants received peripheral intravenous $10 \%$ glucose until randomisation. Infants randomised to the P-PN group commenced the intervention solutions at a median of $18 \mathrm{~h}$ of age (IQR $11-26 \mathrm{~h}$ ). The number of days requiring intravenous therapy were similar between groups (P-PN 5.9, SD 1.9 d, control 5.7, SD 1.3 d; adjusted ratio of means $1.0,95 \%$ CI 0.9 to $1.1, P=0.5$ ). Infants randomised to P-PN had significantly higher parenteral protein, lipid and energy intake in week 1 (Supplementary Table 2, Additional File). There were no significant differences in enteral protein, lipid or energy intake between groups over the three-week study period (Supplementary Table 2, Additional File).

Table 2 Growth outcomes

\begin{tabular}{|c|c|c|c|c|}
\hline Outcome & P-PN $(n=42)$ & Control $(n=50)$ & $\begin{array}{l}\text { Adjusted mean } \\
\text { difference }(95 \% \mathrm{Cl})\end{array}$ & $\begin{array}{l}\text { Adjusted } \\
P \text { value }^{\mathrm{a}} \\
\end{array}$ \\
\hline Weight gain from birth to day $21, \mathrm{~g} / \mathrm{d}$ & $18.7(6.6)$ & $14.8(6.0)$ & 3.9 (1.3 to 6.6$)$ & 0.004 \\
\hline Per protocol weight gain from birth to day $21, \mathrm{~g} / \mathrm{d}^{\mathrm{b}}$ & $19.3(6.3)$ & $14.8(6.1)$ & $4.4(1.9$ to 7.0$)$ & 0.0008 \\
\hline Birthweight regained, $\mathrm{d},(n=41 / 49)$ & $9.8(2.9)$ & $12.3(2.8)$ & $0.8(0.7 \text { to } 0.9)^{c}$ & $<0.0001$ \\
\hline Weight gain from birth to discharge home, $\mathrm{g} / \mathrm{d},(n=42 / 49)$ & $24.1(5.3)$ & $19.4(8.4)$ & 4.9 (2.0 to 7.8$)$ & 0.001 \\
\hline Length gain from birth to discharge home, $\mathrm{mm} / \mathrm{d},(n=39 / 48)$ & $1.2(0.5)$ & $1.0(0.7)$ & $0.3(0.0$ to 0.5$)$ & 0.02 \\
\hline Head circumference gain from birth to discharge home, $\mathrm{mm} / \mathrm{d}$, $(n=39 / 47)$ & $0.9(0.4)$ & $0.9(0.4)$ & $0.1(-0.1$ to 0.2$)$ & 0.4 \\
\hline Weight at day $21, \mathrm{~g}^{\mathrm{d}}$ & $2087(332)$ & $2042(340)$ & 76 (24 to 129$)$ & 0.004 \\
\hline Length at day $21 \pm 2$ days, $\mathrm{cm},(n=28 / 34)^{\mathrm{d}}$ & $44.5(2.8)$ & $43.4(2.1)$ & $1.3(0.5$ to 2.1$)$ & 0.001 \\
\hline Head circumference at day $21 \pm 2$ days, $\mathrm{cm},(n=28 / 34)^{\mathrm{d}}$ & $31.0(2.0)$ & $31.0(1.4)$ & $0.2(-0.3$ to 0.6$)$ & 0.5 \\
\hline Weight on discharge home, $g,(n=42 / 49)^{d}$ & $2561(328)$ & $2463(359)$ & 129 (4 to 254$)$ & 0.05 \\
\hline Length on discharge home, $\mathrm{cm},(n=39 / 48)^{\mathrm{d}}$ & $45.8(2.3)$ & $45.3(2.2)$ & $0.7(0.2$ to 1.5$)$ & 0.1 \\
\hline Head circumference on discharge home, $\mathrm{cm},(n=39 / 47)^{d}$ & $32.8(1.2)$ & $32.8(1.7)$ & $0.1(0.5$ to 0.7$)$ & 0.7 \\
\hline
\end{tabular}

Data are presented as mean (SD)

${ }^{a}$ Adjusted for sex and gestational age $30^{+0}$ to $31^{+6}$ and $32^{+0}$ to $33^{+6}$ weeks

${ }^{b}$ Per protocol analysis included infants whose clinical care adhered to the study protocol, i.e. received P-PN and Control via peripheral line: P-PN $n=39$,

Control $n=49$

c Adjusted ratio of means

${ }^{\mathrm{d}}$ Additionally adjusted for corresponding anthropometric measure at birth 


\section{Primary outcome}

Infants randomised to P-PN had a significantly greater rate of weight gain from birth to day 21 compared with infants randomised to control (P-PN 18.7, SD $6.6 \mathrm{~g} / \mathrm{d}$ vs control 14.8, SD $6.0 \mathrm{~g} / \mathrm{d}$; adjusted mean difference $3.9 \mathrm{~g} /$ d, 95\% CI 1.3 to $6.6 ; P=0.004$ ) (Table 2). The effect was similar (P-PN 19.3, SD $6.3 \mathrm{~g} / \mathrm{d}$ vs control 14.8, SD $6.1 \mathrm{~g} /$ $\mathrm{d}$; adjusted mean difference $4.4 \mathrm{~g} / \mathrm{d}, 95 \%$ CI 1.9 to 7.03 ; $P=0.0008$ ) when analysed per protocol, i.e. excluding the 4 infants who required a central line and received 'standard preterm PN' [14] and SMOFlipid ${ }^{\oplus}$ (Table 2).

\section{Secondary outcomes \\ Growth}

Infants randomised to P-PN regained birthweight significantly faster than infants randomised to control (adjusted ratio of means 0.8 days, $95 \% \mathrm{CI}$ : 0.7 to $0.9 ; P<$ 0.0001) (Table 2). Weight and length at day 21 were significantly higher in the P-PN group compared with control (Table 2). By discharge home weight, but not length, remained significantly higher. There was no difference in head circumference at either time point (Table 2). On discharge home, the rate of weight gain from birth remained significantly greater in infants randomised to
P-PN than those randomised to control (adjusted mean difference $4.9 \mathrm{~g} / \mathrm{d}, 95 \%$ CI 2.0 to $7.8 \mathrm{~g} / \mathrm{d} ; P=0.001)$. Length gain to discharge home was also significantly greater in P-PN infants compared with control (adjusted mean difference $0.3 \mathrm{~mm} / \mathrm{d}, 95 \%$ CI 0.0 to $0.5 \mathrm{~mm} / \mathrm{d} ; P=$ $0.02)$, however there were no differences in rate of head circumference gain (Table 2). The P-PN group had an overall greater body weight z-score compared with control (adjusted mean difference $0.2,95 \%$ CI 0.04 to 0.3 ; $P=0.008)$ (Fig. 2).

\section{Clinical outcomes}

There were no significant differences between groups in the proportion of infants treated for hypoglycemia or developing feeding intolerance, or in days taken to reach full enteral feeds (Table 3). There were no significant differences in any clinical outcomes including respiratory support requirements, incidence of sepsis and length of hospital stay (Table 3 and Supplementary Table 3, Additional File).

\section{Biochemistry}

There was a significant group by time interaction for both mean BUN and mean triglyceride levels $(P<$

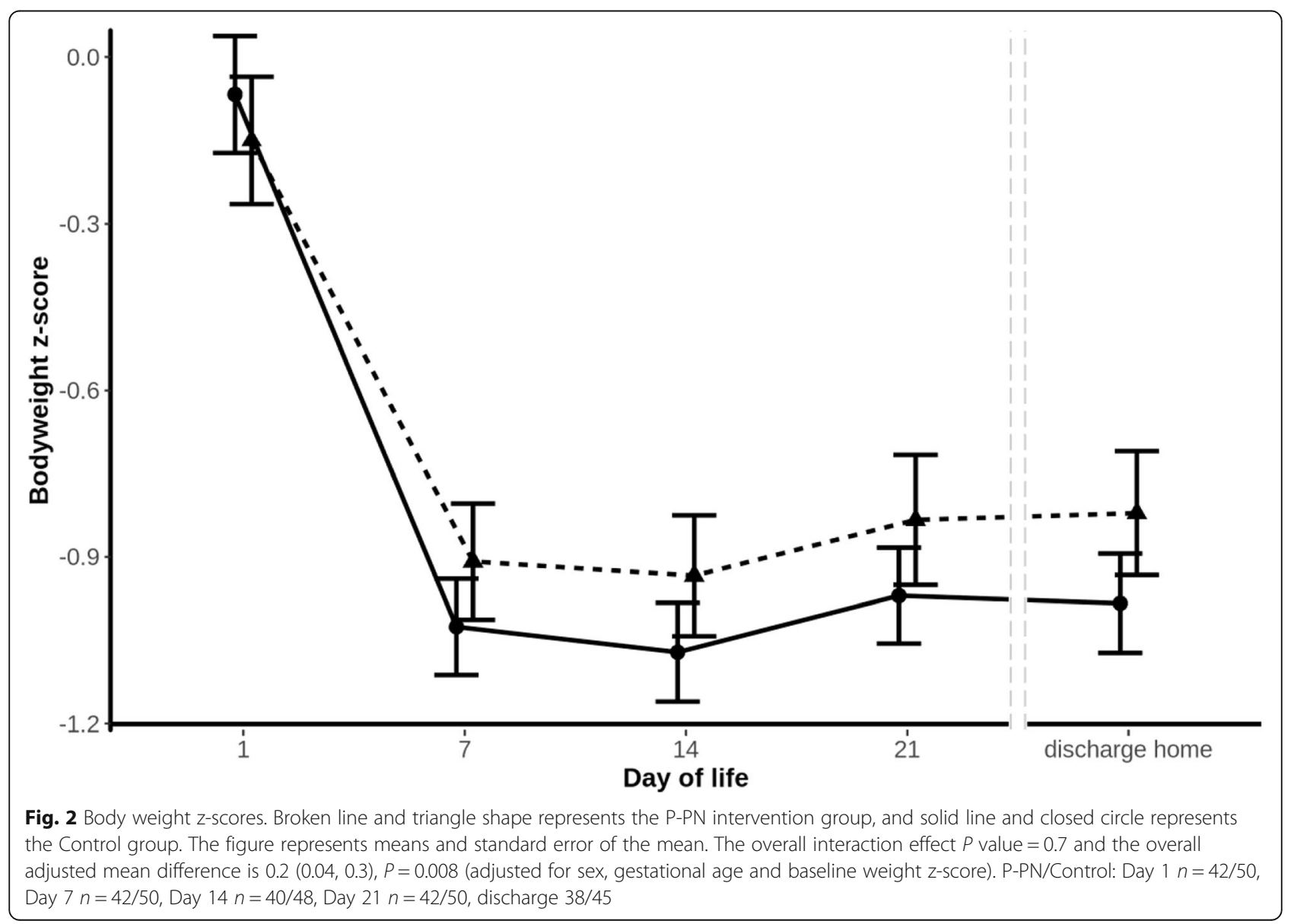


Table 3 Clinical outcomes

\begin{tabular}{|c|c|c|c|c|}
\hline Outcome & P-PN $(n=42)$ & Control $(n=50)$ & Adjusted effect $^{\mathrm{a}}(95 \% \mathrm{Cl})$ & Adjusted $P$ value $^{\mathrm{a}}$ \\
\hline Days of feeding intolerance, mean, SD, $d^{b}$ & $0.6(1.2)$ & $0.6(1.0)$ & $1.0(0.5,2.1)^{c}$ & 1.0 \\
\hline Days to full enteral feeds $(120 \mathrm{mLs} / \mathrm{kg} / \mathrm{d})$, mean, $S D, d$ & $6.6(2.4)$ & $6.2(1.7)$ & $1.1(0.9,1.2)^{c}$ & 0.3 \\
\hline Hypoglycemia requiring treatment & $4.0(9.5)$ & $8.0(16.0)$ & $0.5(0.1,2.0)^{d}$ & 0.4 \\
\hline IPPV via endotracheal tube & $3.0(7.1)$ & $4.0(8.0)$ & $1.1(0.2,5.9)^{d}$ & 0.9 \\
\hline Nasal CPAP & $26.0(61.9)$ & $37.0(74.0)$ & $0.6(0.2,1.5)^{d}$ & 0.3 \\
\hline Days of any respiratory support, mean, SD, $d$ & $4.2(7.0)$ & $5.3(12.0)$ & $0.8(0.4,1.5)^{c}$ & 0.5 \\
\hline Confirmed sepsis $^{\mathrm{e}}$ & $2(4.8)$ & $1(2.0)$ & $2.1(0.2,19.0)^{d}$ & 0.5 \\
\hline Breastmilk (any) on discharge home $(n=38 / 46)$ & $33(87)$ & $41(89)$ & $0.8(0.2,3.3)^{d}$ & 0.8 \\
\hline Length of hospital stay, mean, SD, d & $35.5(10.5)$ & $35.6(13.8)$ & $1.0(0.9,1.1)^{\mathrm{c}}$ & 0.8 \\
\hline
\end{tabular}

Data are presented as $\mathrm{n}(\%)$ unless otherwise indicated

${ }^{a}$ Adjusted for sex and gestational age $30^{+0}$ to $31^{+6}$ and $32^{+0}$ to $33^{+6}$ weeks

b Number of days on which one or more feeds were stopped

${ }^{c}$ Adjusted ratio of means

d Adjusted odds ratio

e P-PN group rhinovirus $n=1$, central line sepsis $n=1$; Control group rhinovirus $n=1$

0.0001) with BUN levels significantly increased to day 7 and triglyceride levels to day 14 in the P-PN group compared with control (Supplementary Table 5, Additional File). However, there were no instances of raised BUN levels $(14.3 \mathrm{mmol} / \mathrm{L}$ [26]) in either group (Supplementary Table 6, Additional File). Hypertriglyceridemia ( $>2.25$ $\mathrm{mmol} / \mathrm{L}$ [27]) occurred in four infants, one each in the P$\mathrm{PN}$ and control group on days 2 and 7 (Supplementary Table 6, Additional File). There were no significant differences between the groups for mean levels of serum albumin, $\mathrm{pH}$, base excess and blood sugar (Supplementary Table 5, Additional File) nor in proportion of infants with low serum albumin, hyperglycaemia or metabolic acidosis (Supplementary Table 6, Additional File).

\section{Adverse events}

Neither the overall length of time that peripheral venous cannulae were required, the frequency of infiltration nor the number of peripheral cannulae used differed between groups (Supplementary Table 4, Additional File). There was one stage 3 extravasation in the P-PN group which resolved quickly on removal of the cannula. There were no stage 3 or 4 extravasations in the control group.

\section{Discussion}

In this single centre, randomised controlled trial, in preterm infants born 30 to 33 weeks' gestation requiring intravenous fluids, peripheral intravenous parenteral nutrition (8\% glucose, $30 \mathrm{~g}$ amino acids/L, heparin $500 \mathrm{IU} /$ L) and SMOFlipid ${ }^{\circ}$ resulted in a significantly greater rate of weight gain from birth to 21 days of age when compared with peripheral intravenous $10 \%$ glucose.

The increased rate of weight gain was maintained to discharge home. The time to regain birthweight in P-PN infants was significantly less than control infants with P$\mathrm{PN}$ infants weighing significantly more at 21 days of age and on discharge home. Length gain from birth to 21 days and birth to discharge home were also significantly greater with the intervention, however, there was no effect on head circumference. We found no evidence of adverse effects relating to the P-PN intervention.

To the best of our knowledge this is the first randomised controlled trial of parenteral nutrition in this population. Previous observational reports show wide variation in clinical practice between countries and centres reflecting the lack of evidence in the nutritional management of this population [10, 11, 28-30]. Delivery of parenteral nutrition using a central line is common in some centers [29, 31] and has been reported to improve nutrient intake and postnatal growth [31]. Central lines allow infusion of high osmolarity parenteral nutrition however their use is not without clinical risk, for e.g., sepsis, haemorrhage, thrombosis, air leak syndromes [13, 32, 33]. Consequently, insertion and care of central lines requires particular expertise, necessitating admission to a neonatal intensive care setting. Caution regarding insertion of central lines in infants who are expected to reach full enteral feeds within $\approx 5-7$ days may explain some of the variation in nutritional management practices. Results from a recent Australian and New Zealand survey [10] and a UK audit [11] in infants born $32-34$ weeks' gestation show that $<20 \%$ use parenteral nutrition in this population with resulting suboptimal nutrient intakes [11].

Our study is unique in that parenteral nutrition was administered via peripheral venous catheter, thus avoiding the use of a central line, and reducing need for intensive care, while maximising nutritional intake. Zecca et al. [34] studied a different approach to improving nutrition in their randomised controlled of a proactive feeding regimen' (enteral intake $100 \mathrm{mLs} / \mathrm{kg} / \mathrm{d}$ day 1 , increasing by day 3 to $200 \mathrm{mLs} / \mathrm{kg} / \mathrm{d}$ ) vs standard care (enteral intake $60 \mathrm{mLs} / \mathrm{kg} / \mathrm{d}$ day 1 , increasing by day 9 to 
$170 \mathrm{~mL} / \mathrm{kg} / \mathrm{d})$. They showed a significant reduction in length of stay (mean, 9.8, SD 3.1 vs 11.9, SD 4.7 days; $P=0.03)$, need for intravenous fluids ( $2.8 \%$ vs $33.3 \%$; $P=$ 0.001 ) with no difference in feeding tolerance. However, their population was considerably more mature (32-36 weeks' gestation) with the trial specifically designed for infants small for gestational age. Their approach may not translate to the less mature infant and such a study would need to be repeated in this population.

During the conduct of this study results from a large $(n=1440)$ RCT suggested that delaying the introduction of parenteral nutrition for 7 days is advantageous in critically ill children $[35,36]$. Only $15 \%(n=209)$ of participants in their study were neonates and all were term born, it is therefore unknown if this benefit would apply to infants with the degree of prematurity included in our study and who had mild transitional problems. Observational studies in the moderately preterm infant have shown an association between minimising postnatal weight losses and improved growth rate [37]. In the extremely preterm infant poor postnatal growth is not only associated with serious complications of prematurity such as bronchopulmonary dysplasia, necrotising enterocolitis and sepsis but also poorer neurodevelopment [5, $6,38,39$ ]. Sufficiently powered randomised controlled trials will be required to detect differences in these less common clinical outcomes in the moderately preterm infant, and effects on longer term neurodevelopment.

Although a economic analysis was beyond the scope of this study, we acknowledge there is a marginal increase in costs associated with the use of intravenous parenteral nutrition compared with $10 \%$ glucose. However, the increase in growth we found will allow 30-33 week preterm infants to remain in hospitals providing Special Care only without need to transfer to a major perinatal center for intensive care with potential reduction in health care costs.

The peripheral parenteral nutrition solution used was specifically designed to have an osmolarity comparable to that of those fluids routinely used peripherally in our institution $(<700 \mathrm{mOsmol} / \mathrm{L})$ thus minimising the risk of phlebitis and extravasation injuries associated with hyperosmolar solutions. The osmolarity of the available standardised formulations exceeded this range [25]. We achieved the reduction in osmolarity by reducing the glucose concentration to $8 \%$ to accommodate the addition of protein. The solution did not include additional electrolytes that may not be essential for the 30 to 33 week preterm newborn in the early days of life and which may increase the risk of extravasation injuries. The osmolarity of this infusate was calculated to be $678 \mathrm{mOsmol} / \mathrm{L}$ which sits within both the European [13] and North American [40] guidelines for peripheral administration and therefore could be used in both neonatal intensive and special care nurseries.
We found no adverse events associated with the intervention. Although there was one grade 3 extravasation in the intervention group this rapidly resolved on removal of the cannula without any further intervention. The parenteral nutrition and lipid intervention were well tolerated. While the BUN levels were higher in the first week of life in the P-PN infants than in the control there were no instances of abnormally high levels, nor was there any evidence of metabolic acidosis. Hypertriglycidaemia occurred in only one infant in each group, with the infant in the control group not having received intravenous lipids; and instances of both hypo- and hyperglycemia were similar between groups.

Our study was limited by not being able to blind the intervention. The study team considered many options for blinding such as having the intervention and control fluids masked within amber opaque syringes and infusion tubing. However, safety considerations were thought to be prohibitive for this strategy. Data analysts were blinded to group allocation and unblinding did not occur until all analyses according to the a priori statistical analysis plan were complete. The randomisation schedule error resulted in simple rather than blocked randomisation. While this led to a small imbalance in numbers between groups (P-PN 42, control 50), sex and gestational age strata were balanced between groups. A further limitation was that secondary outcomes were analysed without adjustment for multiple comparisons. Although treatment effects on secondary growth and biochemistry outcomes were clinically plausible and often highly statistically significant, the lack of multiplicity adjustment means these findings should be interpreted with additional caution.

\section{Conclusion}

Providing peripherally administered parenteral nutrition of $8 \%$ glucose, $30 \mathrm{~g} / \mathrm{L}$ amino acids and SMOFlipid ${ }^{\circ}$ improves short-term weight and length gain in infants born 30-33 weeks' gestation.

\section{Supplementary information}

Supplementary information accompanies this paper at https://doi.org/10. 1186/s12887-020-02280-W.

Additional file 1: Supplementary Table 1. Baseline characteristics. Supplementary Table 2. Parenteral and enteral intake over 21 day study period. Supplementary Table 3. Clinical outcomes.

Supplementary Table 4. Peripheral intravenous cannula.

Supplementary Table 5. Mean biochemical measures by day of life and overall. Supplementary Table 6. Biochemical measures outside normal clinical parameters.

Abbreviations

BUN: Blood urea nitrogen; IQR: Interquartile range; P-PN: Peripheral parenteral nutrition; SD: Standard deviation 


\section{Acknowledgements}

We thank the families who participated in this study. We also thank the Neonatal Intensive and Special Care nurses, midwives and medical practitioners for the value they place on research as an integral part of clinical care by consenting and enrolling participants during their busy shifts.

\section{Authors' contributions}

CCA, AJM, CTC, RAG conceptualised and designed the study, interpreted the data and critically reviewed and revised the manuscript. DB conceptualised and designed the study, undertook data collection and critically reviewed and revised the manuscript. HS undertook data collection, contributed to analyses and data interpretation, drafted the initial manuscript, and critically reviewed and revised the manuscript. TRS supervised the analyses, contributed to data interpretation and critically reviewed and revised the manuscript. All authors approved the final manuscript as submitted and agree to be accountable for all aspects of the work.

\section{Funding}

Supported by a grant from the Women's and Children's Hospital Foundation. The funder was not involved in the study design nor in the collection, analysis, and interpretation of data or the decision to submit for publication. Dr. Suganuma was supported by an overseas study scholarship from Kamisu Saiseikai Hospital, Ibaraki Prefecture, Japan. A/Professor Collins and Professor Gibson are in receipt of National Health and Medical Research Council (NHMRC) Fellowships (APP1132596 and APP1046207 respectively). The views expressed in this article are solely the responsibility of the authors and do not reflect the views of the NHMRC.

\section{Availability of data and materials}

Deidentified individual participant data will be made available to researchers who provide a methodologically sound proposal for use in achieving the goals of the approved proposal. Proposals should be submitted to the corresponding author for review by the trial steering committee.

\section{Ethics approval and consent to participate}

Ethics approval for the study was given by the Human Research Ethics Committee of the Women's and Children's Health Network, Adelaide, South Australia (HREC/15/WCHN/134) and written informed parental consent was obtained to participate in the study.

\section{Consent for publication}

Not applicable.

\section{Competing interests}

Professor Gibson has a patent 'Stabilising and Analysing Fatty Acids in a Biological Sample Stored on Solid Media' licensed to Adelaide Research and Innovation, University of Adelaide. Professor Gibson served on the Fonterra Scientific Advisory Board (to September 2018), honorarium was paid to support travel and consulting time. The remaining authors have no conflicts of interest relevant to this article to disclose.

\section{Author details}

'SAHMRI Women and Kids, South Australian Health and Medical Research Institute Adelaide, South Australia, Australia. ${ }^{2}$ Discipline of Paediatrics, Adelaide Medical School, The University of Adelaide, Adelaide, SA, Australia. ${ }^{3}$ Neonatal Medicine, Women's and Children's Hospital, Adelaide, SA, Australia. ${ }^{4}$ School of Public Health, The University of Adelaide, Adelaide, SA, Australia. ${ }^{5}$ School of Agriculture Food and Wine, The University of Adelaide, Adelaide, SA, Australia.

Received: 17 April 2020 Accepted: 7 August 2020

Published online: 17 August 2020

\section{References}

1. Anderson PJ. Neuropsychological outcomes of children born very preterm. Semin Fetal Neonatal Med. 2014;19(2):90-6.

2. van Baar AL, Vermaas J, Knots E, de Kleine MJK, Soons P. Functioning at school age of moderately preterm children born at 32 to 36 Weeks' gestational age. Pediatrics. 2009;124(1):251-7.

3. Quigley MA, Poulsen G, Boyle E, Wolke D, Field D, Alfirevic Z, et al. Early term and late preterm birth are associated with poorer school performance at age 5 years: a cohort study. Arch Dis Child Fetal Neonatal Ed. 2012;97(3): F167-73.

4. Cserjesi R, Van Braeckel KN, Butcher PR, Kerstjens JM, Reijneveld SA, Bouma A, et al. Functioning of 7-year-old children born at 32 to 35 weeks' gestational age. Pediatrics. 2012;130(4):e838-46.

5. Belfort MB, Rifas-Shiman SL, Sullivan T, Collins CT, McPhee AJ, Ryan P, et al. Infant growth before and after term: effects on neurodevelopment in preterm infants. Pediatrics. 2011;128(4):e899-906.

6. Ehrenkranz RA, Dusick AM, Vohr BR, Wright LL, Wrage LA, Poole WK, et al. Growth in the neonatal intensive care unit influences neurodevelopmental and growth outcomes of extremely low birth weight infants. Pediatrics. 2006;117(4):1253-61.

7. van Goudoever JB, Carnielli V, Darmaun D, Sainz de Pipaon M, Braegger C, Bronsky J, et al. ESPGHAN/ESPEN/ESPR/CSPEN guidelines on pediatric parenteral nutrition: Amino acids. Clin Nutr. 2018;37(6, Part B):2315-23.

8. Lapillonne A, Fidler Mis N, Goulet O, van den Akker CHP, Wu J, Koletzko B, et al. ESPGHAN/ESPEN/ESPR/CSPEN guidelines on pediatric parenteral nutrition: Lipids. Clin Nutr. 2018;37(6, Part B):2324-36.

9. Lapillonne A, Bronsky J, Campoy C, Embleton N, Fewtrell M, Fidler Mis N, et al. Feeding the late and moderately preterm infant: a position paper of the European Society for Paediatric Gastroenterology, Hepatology and nutrition committee on nutrition. J Pediatr Gastroenterol Nutr. 2019;69(2): 259-70.

10. Alexander T, Bloomfield FH. Nutritional management of moderate-late preterm infants: survey of current practice. J Paediatr Child Health. 2019; 55(3):338-42.

11. Brown $\mathrm{K}$, Johnson MJ, Leaf AA. Suboptimal nutrition in moderately preterm infants. Acta Paediatr. 2014;103(11):e510-2.

12. Kolaček S, Puntis JWL, Hojsak I, Braegger C, Bronsky J, Cai W, et al. ESPG HAN/ESPEN/ESPR/CSPEN guidelines on pediatric parenteral nutrition: Venous access. Clin Nutr. 2018;37(6, Part B):2379-91.

13. Hartman C, Shamir R, Simchowitz V, Lohner S, Cai W, Decsi T, et al. ESPG HAN/ESPEN/ESPR/CSPEN guidelines on pediatric parenteral nutrition: Complications. Clin Nutr. 2018;37(6, Part B):2418-29.

14. Bolisetty S, Osborn D, Schindler T, Sinn J, Deshpande G, Wong CS, et al. Standardised neonatal parenteral nutrition formulations - Australasian neonatal parenteral nutrition consensus update 2017. BMC Pediatr. 2020; 20(1):59.

15. Pittiruti M, Hamilton H, Biffi R, MacFie J, Pertkiewicz M. ESPEN guidelines on parenteral nutrition: central venous catheters (access, care, diagnosis and therapy of complications). Clin Nutr. 2009;28(4):365-77.

16. Moher D, Hopewell S, Schulz KF, Montori V, Gøtzsche PC, Devereaux PJ, et al. CONSORT 2010 explanation and elaboration: updated guidelines for reporting parallel group randomised trials. J Clin Epidemiol. 2010;63(8):e1e37.

17. Harris PA, Taylor R, Thielke R, Payne J, Gonzalez N, Conde JG. Research electronic data capture (REDCap)--a metadata-driven methodology and workflow process for providing translational research informatics support. J Biomed Inform. 2009:42(2):377-81.

18. Harris PA, Taylor R, Minor BL, Elliott V, Fernandez M, O'Neal L, et al. The REDCap consortium: Building an international community of software platform partners. J Biomed Inform. 2019;95:103208.

19. Montgomery LA, Hanrahan K, Kottman K, Otto A, Barrett T, Hermiston B. Guideline for IV infiltrations in pediatric patients. Pediatr Nurs. 1999;25(2): 167-80.

20. Chow SSW, Le Marsney R, Haslam R, Lui K. Report of the Australian and New Zealand neonatal network 2014. Sydney: ANZNN; 2016.

21. National Health and Medical Research Council. Infant Feeding Guidelines. Canberra: National Health and Medical Research Council; 2012

22. Miller J, Makrides M, Gibson RA, McPhee AJ, Stanford TE, Morris S, et al. Effect of increasing protein content of human milk fortifier on growth in preterm infants born at $<31$ wk gestation: a randomized controlled trial. Am J Clin Nutr. 2012;95(3):648-55.

23. Beeby PJ, Bhutap T, Taylor LK. New South Wales population-based birthweight percentile charts. J Paediatr Child Health. 1996;32(6):512-8.

24. R Core Team. A language and environment for statistical computing. http:// www.R-project.org/. Published 2019. Accessed July, 2019.

25. Bolisetty S, Osborn D, Sinn J, Lui K, Australasian Neonatal Parenteral Nutrition Consensus G. Standardised neonatal parenteral nutrition formulations - an Australasian group consensus 2012. BMC Pediatr. 2014:14: 48 
26. Osborn DA, Schindler T, Jones $\sqcup$, Sinn JKH, Bolisetty S. Higher versus lower amino acid intake in parenteral nutrition for newborn infants. Cochrane Database Syst Rev. 2018; Issue 3. Art. No.: CD005949. https://doi.org/10. 1002/14651858.CD005949.pub2.

27. Kapoor V, Malviya MN, Soll R. Lipid emulsions for parenterally fed preterm infants. Cochrane Database Syst Rev. 2019; Issue 6. Art. No.: CD013163. https://doi.org/10.1002/14651858.CD013163.pub2.

28. Boyle EM, Johnson S, Manktelow B, Seaton SE, Draper ES, Smith LK, et al. Neonatal outcomes and delivery of care for infants born late preterm or moderately preterm: a prospective population-based study. Arch Dis Child Fetal Neonatal Ed. 2015;100(6):F479-85.

29. lacobelli S, Viaud M, Lapillonne A, Robillard PY, Gouyon JB, Bonsante F, et al. Nutrition practice, compliance to guidelines and postnatal growth in moderately premature babies: the NUTRIQUAL French survey. BMC Pediatr. 2015;15(1):110

30. Kirkby S, Greenspan JS, Kornhauser M, Schneiderman R. Clinical outcomes and cost of the moderately preterm infant. Adv Neonatal Care. 2007;7(2): 80-7.

31. Smazal AL, Kavars AB, Carlson SJ, Colaizy TT, Dagle JM. Peripherally inserted central catheters optimize nutrient intake in moderately preterm infants. Pediatr Res. 2016;80(2):185-9.

32. Cartwright DW. Central venous lines in neonates: a study of 2186 catheters. Arch Dis Child Fetal Neonatal Ed. 2004;89(6):F504-8.

33. Shalabi M, Adel M, Yoon E, Aziz K, Lee S, Shah PS. Risk of infection using peripherally inserted central and umbilical catheters in preterm neonates. Pediatrics. 2015;136(6):1073-9.

34. Zecca E, Costa S, Barone G, Giordano L, Zecca C, Maggio L. Proactive Enteral Nutrition in Moderately Preterm Small for Gestational Age Infants: A Randomized Clinical Trial. J Pediatr. 2014;165(6):1135-1139.e1131.

35. Fivez T, Kerklaan D, Mesotten D, Verbruggen S, Wouters PJ, Vanhorebeek I, et al. Early versus late parenteral nutrition in critically ill children. N Engl J Med. 2016;374(12):1111-22.

36. van Puffelen E, Vanhorebeek I, Joosten KFM, Wouters PJ, Van den Berghe G, Verbruggen $\mathrm{S}$. Early versus late parenteral nutrition in critically ill, term neonates: a preplanned secondary subgroup analysis of the PEPaNIC multicentre, randomised controlled trial. Lancet Child Adolesc Health. 2018; 2(7):505-15.

37. Blackwell MT, Eichenwald EC, McAlmon K, Petit K, Linton PT, McCormick MC, et al. Interneonatal intensive care unit variation in growth rates and feeding practices in healthy moderately premature infants. J Perinatol. 2005;25(7): 478-85.

38. Ehrenkranz RA, Das A, Wrage LA, Poindexter BB, Higgins RD, Stoll BJ, et al. Early nutrition mediates the influence of severity of illness on extremely LBW infants. Pediatr Res. 2011;69(6):522-9.

39. Vinall J, Grunau RE, Brant R, Chau V, Poskitt KJ, Synnes AR, et al. Slower postnatal growth is associated with delayed cerebral cortical maturation in preterm newborns. Sci Transl Med. 2013;5(168):168ra168.

40. American Society for Parenteral Enteral Nutrition. Guidelines for the Use of Parenteral and Enteral Nutrition in Adult and Pediatric Patients. JPEN J Parenter Enteral Nutr. 2002;26(1 suppl):1SA-138SA.

\section{Publisher's Note}

Springer Nature remains neutral with regard to jurisdictional claims in published maps and institutional affiliations.

Ready to submit your research? Choose BMC and benefit from:
- fast, convenient online submission
- thorough peer review by experienced researchers in your field
- rapid publication on acceptance
- support for research data, including large and complex data types
- gold Open Access which fosters wider collaboration and increased citations
- maximum visibility for your research: over 100M website views per year
At BMC, research is always in progress.
Learn more biomedcentral.com/submissions

